\title{
The Effect of Religious Beliefs, Participation and Values on Corruption: Survey Evidence from Iraq
}

\author{
Marwah Abdulkareem Mahmood Zuhaira \\ School of Management, Harbin Institute of Technology \\ Harbin, China
}

\author{
Tian Ye-zhuang \\ School of Management, Harbin Institute of Technology \\ Harbin, China
}

\begin{abstract}
This research tests the role that religious beliefs, rituals and values plays on the corruption in Iraq. Furthermore, the research assesses ethical and moral ideals pertinent to religion, in the Iraqi educational sector. Correlation analysis and linear regression help assess the relations among the study's constructs and variables. The hypotheses tested by multiple regression technique with the help of SPSS software. Grounded in the data collected from 600 employees, the results affirm that religious beliefs have negative association with levels of corruption. Prayers in religious institution are influenced by the clergy, which serves as a set of life instructions to avoid corrupt practices. The generalizability of our results might be limited because we surveyed workers from a single sector; this calls for future studies to verify the stability of our findings across another sectors and firms.
\end{abstract}

\section{Keywords-Beliefs; participation; values; corruption}

\section{INTRODUCTION}

Corruption is seen as one of the bad behaviors, in view of this, international organizations, governments and donors are looking for mechanisms to fight it. Corruption as an immoral behavior includes a deviation from the rules, laws and moral values. Corrupt actors benefit from the power entrusted to them for personal benefits [1]. The most famous definition of corruption is the use of public power for private gain [2]. Several attempts to fight corruption has always let to disappointing results, and this has prompted the United Nations Development Program (UNDP) to highlight on the social changes and behavior in this issue [3].

It has been discussed that in countries where religion plays role in the lives of most humans, many individuals, including workers, are likely to derive their ethical framework in part from their religion. Religion supplied many with the language of moral, ethics and often an actual 'list' of rules to live by, some of which can be explained as being of particular importance to fighting corruption. The basis for the growing attention given to the religion-corruption relation generally stems from the argument that fairness and sincerity form the basis of many religions, and as such, religious leaders can be utilized in the war against corruption [4], [5]. Developing countries are experiencing increased cases of using religion to curb corruption. Systemic studies on religious factors for individuals, Mutascu (2010) confirmed that religion significantly have affected corruption [6]. Lopez (2014) Proved religion employees negatively related to corruption levels [68]. Porta et al. (1999) [7] and Treisman (2000) [8] found religious mores of employees have been using cultural attitudes towards social hierarchy. Wherever more hierarchical religions such as Islam dominate Catholicism, Eastern Orthodoxy, defies to office-holders might be scarce than in cultures shaped by more equality and individualistic religions, such as Protestantism. In addition, religions may explain how individuals seeing their loyalties to them organization contrary to other organizations. Through the historical pattern of influence that sophisticated in different settings between religious institutions and state, religion could affect corruption levels. In religious practice such as Protestantism, the religious institutions may play an important role in denouncing and monitoring abuses by state employees.

Faith in the afterlife reduces corruption. As a matter of fact, religious leaders speak publicly about suspicious practices within religious establishments when individuals participates in religious rituals [5]. Religious participation is working to support and strengthen the cohesion of confidence within the religious groups [9], as well as enable the individual to deal with negative and stressful events and turn the individual to pray to ease the psychological pressure [10]. Religious leaders often interact with individuals belonging to the same community, to provide strict guidance on behavior and lifestyles [9] as well as teaching them to prevent believers from participating in corrupt activities [11]. However, this can be influenced by cults. And as it turns out to be, cult is one of the factors that decreases corruption [5]. Also Marshall and Van Saanen (2007) added that, religious institutions, leaders and networks offer a powerful potential force in raising governance standards in the work of development. Because they have special "expertise" in values and integrity, and because of their extensive presence and reach [12]. From here we can see that the fundamental point is the possibility of the impact of religious participation on corruption [10].

Religious beliefs are linked to ethical abuses, especially in the area of rewards and punishment [9]. Religion promotes equality, condemns deception and rejects corruption [13]. Faith in afterlife is negatively associated with death anxiety, and small experience of life-threatening events is enough to push up an individual's faith [14]. While atheists believe that the individual goes to heaven after death and heaven differs from hell [15], individuals with moderate religious status have a higher death anxiety than the very religious individuals [16]. Although we are not certain about the existence of afterlife, religions working exceedingly to provide a set of beliefs about what happens after death and focus on individuals who are not committed to such beliefs, as such individuals will go to hell in the afterlife [15]. Thus we can ask the question: "Does 
religious belief have a real impact on the levels of corruption"?

Values are a set of principles in the life of individuals [17]. Adherence to religious values require strength, organization, and control to achieve the goals [18]. Through religious values religions provide a set of guidelines on the violations that are forgiven and the ones that should not be forgiven [19]. Here, we must pause for a moment to ask if the values that can be forgiven are those values that encourage individuals to engage in corrupt practices. But [20] found that Muslims are less forgiving than Christians. And by referring to the Corruption Perceptions Index, we can confirm that Muslim countries are the most corrupt than Christians. Therefore, we can temporarily say that the values of forgiveness reduce the levels of corruption.

The study aims to investigate three points for organizational behavior literature. First, whether the increase in religious beliefs reduces corruption levels. Secondly, it aims at the investigation into the subject of an individual's participation in religious rituals and their effect on the transparency and if they discourage corruption level. Finally the values of forgiveness may have an unknown role in changing the levels of corruption. In this study, findings show that the increase in religious beliefs of the individual has increased the fear and provided a good deterrent to corrupt behavior. As long as the individual increases the prayer level, the probability of avoiding corrupt practices is high through the instructions and directives from the clergy group on the basis of the sacred texts.

\section{METHODOLOGY}

\section{A. Main hypotheses}

Several researches deal with the investigation into the issue of religion and corruption but reached contradictory results. Religion provides an internal barrier to move away from corrupt acts [21]. It also provides the basis for moral corruption that weakens[22]. The religious obligation to be more laws and more respected them [23]. In [24], most recent turning point is when the issue of corruption when he stressed the issue to focus on the religious beliefs and especially life after death. In addition, religious participation provides a range of life teachings that enable individuals stay away from corrupt behaviors [25]. Religious values (forgiveness) encourages individuals to stay away from corrupt practices[20]. Therefore, it is hypothesized that:

1) H1: Religious beliefs can decrease corruption levels negatively.

2) H2: Religious participants can decrease corruption levels negatively.

3) H3: Religious values can decrease corruption levels negatively.

\section{B. Participant}

In September 2016, we distributed questionnaires to workers by random-sampling in Iraqi universities, which are the religious areas of Islamic religion. The composition of the participants was more than 18 years. The proportion of males was $65 \%$ whiles that of females was $35 \%$. Using the Likert scale Quintet gradient of (1) strongly agree, and (5) strongly disagree.

\section{Measures}

\section{1) Independent variables}

Current study relies on the survey method to reach the maximum information in a limited time frame. The study used a Likert scale Quintet gradient of (1) strongly agree and (5) strongly disagree.

Religious beliefs were measured through three main dimensions and we set answer choices in a scale of 1-5, where: 1) always, 2) often, 3) sometimes, 4) rarely, 5) never. In the first dimension, faith in God, respondents were asked to determine the level of their faith, "I believe in God". The second dimension, believe in afterlife scale [11], [9], included three items, such us, "I think that there is life after death". The third dimension is death anxiety, which included 11 items derived from the scale [26] [11], for instance, "I am not sure what will be after death and I am very worried".

Religious Participation measure in the fifth set of answers were ranked as follows: 1) Daily, 2) weekly, 3) monthly, 4) a few times a year, 5) never. it has been classified into public ritual consists of two items [27] focused on public religious participation in religious establishments. An example of such question is: "Except at funerals what is your presence in mosques and Shiite mosques rate these days?" Current study also have worked to put items in an attempt to measure the Individual rituals target denomination (Muslims) is composed of four items. Such us "I gave alms to the poor out of my own money". The value scale was based on the scales of [28] and [14], an example is, "I think that corruption actions can be forgiven".

\section{2) Dependent variable}

Four items in the scale of T. Stepurko et al. was adopted to examine corruption [29] to determine the amount of cash or in-kind gifts contained. For example, "Have you ever (or one of your family) paid cash amount on an informal basis to employees in government organizations?" The answer was determined by five choices 1) always, 2) often, 3) sometimes, 4) rarely, 5) never.

\section{DATA ANALYSES AND DISCUSSION}

We conducted multiple regression analysis to estimate the linear hypotheses to find out the role of religious beliefs, participation and values on corruption by SPSS 20 statistics.

Finally, complete content and organizational editing before formatting. Please take note of the following items when proofreading spelling and grammar.

\section{A. Descriptive Statistics}

Descriptive statistics includes mean, standard deviation and bivariate correlation. (Beliefs, rituals and values) had a negative relationship with corruption $(-0.64 * *,-0.61 * *$, $\left.0.47^{* *}\right)$ and $(\mathrm{p}<0.01)$ (Table 1). 
TABLE. I. MEANS, STANDARD DEVIATIONS, AND CORRELATIONS FOR ALL VARIABLES

\begin{tabular}{|c|c|c|c|c|c|c|c|}
\hline Variable & $M$ & $S D$ & 1 & 2 & 3 & 4 & 5 \\
\hline 1. Age & 0.60 & 0.48 & & & & & \\
\hline 2. Gender & 2.57 & 1.11 & $\begin{array}{l}- \\
0.07\end{array}$ & & & & \\
\hline 3. Belief & 3.91 & 1.04 & $\begin{array}{l}- \\
0.03\end{array}$ & $\begin{array}{l}- \\
0.02\end{array}$ & & & \\
\hline 4. Rituals & 4.01 & 1.14 & 0.01 & & $0.88 * *$ & & \\
\hline 5. Values & 3.98 & 0.94 & $\begin{array}{l}- \\
0.01\end{array}$ & 0.01 & $0.77 * *$ & $0.74 * *$ & \\
\hline $\begin{array}{l}6 . \\
\text { Corruption }\end{array}$ & 1.96 & 1.09 & $\begin{array}{l}- \\
0.01\end{array}$ & 0.06 & $\begin{array}{l}- \\
0.64 * *\end{array}$ & $\begin{array}{l}- \\
0.61 * *\end{array}$ & $\begin{array}{l}- \\
0.47 * *\end{array}$ \\
\hline
\end{tabular}

Note: $N=600 .{ }^{*} p<0.05 ; * * p<0.01$

\section{B. Multiple Regression Analysis: Direct Effects of Religious \\ Beliefs, Participation and Values on the Corruption Level}

The multiple regressions examined three models during the effect of religious variables on corruption. As expected, this study models have significantly negative effects on the corruption level, where F-value $=139.74,122.11$ and 59.19, pvalue $<001$, respectively. Model 1,2 and 3, recorded an adjusted R2 of 41, 38 and 23 percent, respectively. In the first model, we estimated the effects of age, gender and employees beliefs on corruption. Religious Beliefs for employees had a negative and significant influence on corruption. It is equivalent to $\left(-0.67^{* *}\right)$ for one per cent increase in corruption level. Age and gender had no influence on corruption. The impact of religious rituals for employees on corruption is negative and significant. It is equivalent to $(-0.59 * *)$. Moreover, for one per cent increase in corruption level, we do not see any impact of gender and age in the second model. Finally, religious value for employees (forgiveness) is negatively associated with corruption $\left(-0.56^{* *}\right)$ for one per cent increase in corruption level.

TABLE. II. Significant Testing Results of THE MultiPle REGRESSION FOR MAIN-HYPOTHESES

\begin{tabular}{|l|l|l|l|l|l|l|}
\hline Model & & & & $\mathbf{R}^{2}$ & $\begin{array}{l}\text { Adju } \\
\text { sted } \\
\mathbf{R}^{2}\end{array}$ & $\begin{array}{l}\text { F- } \\
\text { value }\end{array}$ \\
\hline $\begin{array}{l}\text { 1. Age, } \\
\text { Gender and } \\
\text { Beliefs } \\
\text { (H1)(model 1) }\end{array}$ & $0.05-$ & 0.04 & $-0.67 * *$ \\
0.000 & .410 & 0.41 & $\begin{array}{l}139.7 \\
4\end{array}$ \\
\hline $\begin{array}{l}\text { 2. Age, } \\
\text { Gender, and } \\
\text { Rituals (H2) } \\
\text { (model })\end{array}$ & 0.00 & 0.04 & $-0.59 * *$ \\
\hline $\begin{array}{l}\text { 3. Age, } \\
\text { Gender, and } \\
\text { Values (H3)( } \\
\text { model 3) }\end{array}$ & 0.998 & 0.162 & 0.000 & .380 & 0.38 & 122.1 \\
\hline
\end{tabular}

Note: ${ }^{*} p<0.05 ; * * p<0.01$ standard error in parentheses, $\mathrm{n}=600$.
In the summary of results, religious beliefs, participation and values were negatively and significantly associated with corruption levels, but the effect of age and gender on the corruption level is insignificant (see Table 2).

The beliefs, rituals and values have beta $\beta(-0.64,-0.61$ and - 0.48) respectively on corruption, and standard error $(0.033$, 0.063 , and 0.059 ). The adjusted $\mathrm{R} 2$ is 0.41 , which means that the beliefs explains 41 percent of the variation in corruption, where F- calculated is 139.74 higher than scheduled value. Rituals clarify $38 \%$ and values $23 \%$ of the variation in corruption. Where, F- calculated is 122.11 and 59.19, respectively higher than the scheduled value.

\section{Discussion}

The findings from current study show that beliefs, rituals and values have a relationship with corruption. In order to attain anti-corruption, one must resort to religious beliefs because it has a positive effect on corruption more than rituals. Religious values had a weaker influence on corruption in comparison with beliefs and rituals, but cannot be ignored to this effect.

The participation of individuals in religious rituals may contribute to the withdrawal of the individual from corrupt deals. The increase in religious beliefs may pose a barrier in the fear of doing suspicious business. [25] estimated the coefficient value of religion Sectarian participation on corruption equal $-0.38 \%$. [30] indicated that religion has a positive effect on happiness. They also argued that religiosity affected the sense of injustice as well as the individual's attitudes. Again, there are many reasons lurking behind corruption and injustice. [31] considered a culture of mistrust to reduce the level of transparency and increase corruption in institutions.

The current study ignored the feeling of happiness and its impact on corrupt deals, not to mention the differences in religious affiliation. This study reflects the perceptions of Muslims only and does not include other religions such as Christianity, Judaism, Buddhism and many others, so we deem it necessary to focus on a comparison between the study of religions and among different cultures in future studies. As well, the relationship between religious leaders and corruption is more problematic, and we encourage consideration of this question in future research.

\section{CONCLUSSION}

Corruption is far back in history and widespread in all countries, and all countries try as much as possible to avoid it. Through three independent variables beliefs, participation in rituals and values of religion we tested the possibility of reducing this type of behavior (corruption). We also found out that beliefs in afterlife is possible to contribute to the withdrawal of the individual from corrupt deals. Besides that religious participation would contribute to providing the foundations of guidelines as well acting as a mentor for individuals in daily life, especially when exposed to moral dilemma. However, the current study does not provide any clarification on the feeling of happiness, and the effect of an individual's sense of injustice in the field of corruption. The 
results will be the best if it tested in different environments within different sectors.

\section{ACKNOWLEDGMENT}

I graciously thank Portia Opoku boad to help me in English editing. I also thank Karrar Abdulelah Azeez helped sustain my enthusiasm and energy throughout the project.

\section{REFERENCES}

[1] T. Rabl and T. M. Kühlmann, "Understanding corruption in organizations-development and empirical assessment of an action model," Journal of business ethics, vol. 82, pp. 477-495, 2008.

[2] J. C. Andvig, O.-H. Fjeldstad, I. Amundsen, T. Sissener, and T. Søreide, Corruption. A review of contemporary research: Chr. Michelsen Institute, 2001.

[3] A. C. Gebel, "Human nature and morality in the anti-corruption discourse of transparency international," Public Administration and Development, vol. 32, pp. 109-128, 2012.

[4] J. Luxmoore, "Churches urged to help fight global corruption," Catholic New Times, vol. 23, pp. 12-3, 1999.

[5] H. Marquette, “'Finding God'or 'Moral Disengagement'in the Fight against Corruption in Developing Countries? Evidence from India and Nigeria," Public Administration and Development, vol. 32, pp. 11-26, 2012.

[6] M. I. Mutascu, "Corruption, Social Welfare, Culture and Religion in European Union 27," Transition Studies Review, vol. 16, pp. 908-917, 2010.

[7] R. La Porta, F. Lopez-de-Silanes, A. Shleifer, and R. Vishny, "The quality of government," Journal of Law, Economics, and organization, vol. 15 , pp. 222-279, 1999.

[8] D. Treisman, "The causes of corruption: a cross-national study," Journal of public economics, vol. 76, pp. 399-457, 2000.

[9] Q. D. Atkinson and P. Bourrat, "Beliefs about God, the afterlife and morality support the role of supernatural policing in human cooperation," Evolution and Human Behavior, vol. 32, pp. 41-49, 2011.

[10] A. Fenelon and S. Danielsen, "Leaving my religion: Understanding the relationship between religious disaffiliation, health, and well-being," Social science research, vol. 57, pp. 49-62, 2016.

[11] J. Dezutter, B. Soenens, K. Luyckx, S. Bruyneel, M. Vansteenkiste, B. Duriez, et al., "The role of religion in death attitudes: Distinguishing between religious belief and style of processing religious contents," Death studies, vol. 33, pp. 73-92, 2008.

[12] K. Marshall and M. B. Van Saanen, Development and faith: where mind, heart, and soul work together: World Bank Publications, 2007.

[13] S. L. Adams, "The Justice Imperative in Scripture," Interpretation, vol. 69, pp. 399-414, 2015.

[14] A. B. Cohen, J. D. Pierce, J. Chambers, R. Meade, B. J. Gorvine, and H G. Koenig, "Intrinsic and extrinsic religiosity, belief in the afterlife, death anxiety, and life satisfaction in young Catholics and Protestants," Journal of Research in Personality, vol. 39, pp. 307-324, 2005.

[15] D. Pyne, "An afterlife capital model of religious choice," Journal of Economic Behavior \& Organization, vol. 92, pp. 32-44, 2013.
[16] M. Ardelt and C. S. Koenig, "The role of religion for hospice patients and relatively healthy older adults," Research on Aging, vol. 28, pp. 184-215, 2006.

[17] S. Roccas and S. H. Schwartz, "Church-state relations and the association of religiosity with values: A study of Catholics in six countries," Cross-Cultural Research, vol. 31, pp. 356-375, 1997.

[18] D. Mathras, A. H. Cohen, N. Mandel, and D. G. Mick, "The effects of religion on consumer behavior: A conceptual framework and research agenda," Journal of Consumer Psychology, April, 2016.

[19] N. C. Scull, "Forgiveness, revenge, and adherence to Islam as moderators for psychological wellbeing and depression among survivors of the 1990 Iraqi invasion of Kuwait," Journal of Muslim Mental Health, vol. 9, 2015.

[20] E. Mullet and F. Azar, "Apologies, repentance, and forgiveness: A Muslim-Christian comparison," The International Journal for the Psychology of Religion, vol. 19, pp. 275-285, 2009.

[21] L. Shadabi, "The impact of religion on corruption," The Journal of Business Inquiry, vol. 12, pp. 102-117, 2013.

[22] P. B.-N. Bloom and G. Arikan, "A two-edged sword: The differential effect of religious belief and religious social context on attitudes towards democracy," Political Behavior, vol. 34, pp. 249-276, 2012.

[23] R. Gatti, S. Paternostro, and J. Rigolini, "Individual attitudes toward corruption: do social effects matter?," World Bank Policy Research Working Paper, 2003.

[24] G. Gorer, "The pornography of death," Encounter, vol. 5, pp. 49-52, 1955.

[25] M. Kalin and N. Siddiqui, "Islam's Political Disadvantage: Corruption and Religiosity in Quetta, Pakistan," Politics and Religion, vol. 9, pp. 456-480, 2016

[26] P. T. Wong, G. T. Reker, and G. Gesser, "Death Attitude ProfileRevised: A multidimensional measure of attitudes toward death," Death anxiety handbook: Research, instrumentation, and application, vol. 121, 1994.

[27] B. Torgler, "The importance of faith: Tax morale and religiosity," Journal of Economic Behavior \& Organization, vol. 61, pp. 81-109, 2006.

[28] A. Macaskill, "Defining forgiveness: Christian clergy and general population perspectives," Journal of personality, vol. 73, pp. 1237-1266, 2005.

[29] T. Stepurko, M. Pavlova, I. Gryga, and W. Groot, "Informal payments for health care services-Corruption or gratitude? A study on public attitudes, perceptions and opinions in six Central and Eastern European countries," Communist and Post-Communist Studies, vol. 46, pp. 419431, 2013.

[30] M. Joshanloo and D. Weijers, "Religiosity reduces the negative influence of injustice on subjective well-being: A study in 121 nations," Applied Research in Quality of Life, pp. 1-12, 2015

[31] J. Rowbottom, "CORRUPTION, TRANSPARENCY, AND REPUTATION: THE ROLE OF PUBLICITY IN REGULATING POLITICAL DONATIONS," The Cambridge Law Journal, vol. 75, pp. 398-425, 2016 